\title{
PERFIL DO CONSUMIDOR DE PESCADO NO MUNICÍPIO DE CAMPOS DOS GOYTACAZES - RJ
}

\author{
Rodrigo Martins Pinto \\ Engenheiro de Produção/UCAM-Campos/RJ \\ didigom@yahoo.com.br \\ Vitor Gomes Viana da Silva \\ Engenheiro de Produção/UCAM-Campos/RJ \\ vitorgviana@gmail.com \\ Eduardo Shimoda \\ Doutor em Produção Animal/UENF/RJ \\ eduardo_shimoda@uol.com.br

\section{Vivian Ferreira Pereira} \\ Mestre em Pesquisa Operacional e Inteligência Computacional/UCAM-Campos/RJ \\ vivifpc@hotmail.com
}

\begin{abstract}
Resumo
O presente trabalho visou abordar o consumo do pescado em Campos dos Goytacazes. Foram aplicados 92 questionários. Os estratos foram comparados estatisticamente pelo teste de qui-quadrado. Observou-se que $90 \%$ dos entrevistados consideram a carne de pescado saudável. Foi percebido, ainda, diferença estatística entre o hábito de consumo/pesca de acordo com o gênero. Também foi constatada diferença estatística quanto ao fator que promoveria aumento de consumo de carne de pescado, sendo que homens consumiriam mais peixes se fossem mais fáceis de preparar, enquanto mulheres indicaram que a redução do preço permitiria aumento de consumo. O preço do quilograma de pescado considerado ideal pelos entrevistados seria entre $R \$ 2,01$ e $R \$ 5,00$. A maior parte dos entrevistados afirmou que não existe diferença quanto à preferência da origem do pescado.
\end{abstract}

Palavras-chave: Pescado; Análise de mercado; Peixe

\begin{abstract}
This study aimed to address the consumption of fish in Campos. 92 questionnaires were applied. The strata were statistically compared using the chi-square. It was observed that $90 \%$ of those surveyed consider the flesh of healthy fish. It was noticed also statistical difference between the habit of consumption / fishing in the genre. It was also found statistical difference in the factor that would promote increased consumption of meat of fish, and men consume more fish if they were easier to prepare, while women indicated that the price reduction would increase consumption. The price of a kilogram of fish is considered ideal by respondents would be between $\mathrm{R} \$ 2.01$ and $\mathrm{R} \$ 5.00$. Most of the respondents said there is no difference in the preference of the origin of fish.
\end{abstract}

Keywords: Fish meat; Market analysis; Fish

\section{INTRODUÇÃO}

A carne de peixe foi utilizada como alimento pelos homens primitivos. Através de fragmentos de ossos e de pedras e de desenhos gravados nas cavernas, pode-se deduzir que os homens primitivos eram caçadores e pescadores (SANTOS, 1977).

O peixe é uma excelente fonte de proteínas de alta qualidade e de rápida digestão, rico em nutrientes, como as vitaminas $\mathrm{A}$ e $\mathrm{D}$, que geralmente não são encontrados em alimentos rotineiramente consumidos, além das vitaminas B, E e K e do fósforo (LANKE; MAGAGNIN; FURLONG, 2003). A carne de pescado contém, também, ácidos graxos do tipo Omega-3, componentes que são responsáveis por benefícios comprovados à saúde, sendo, inclusive, por esta razão, aconselhável o consumo de pelo menos três refeições 
com peixe por semana. A carne de peixe é macia e com alta digestibilidade e, com o consumo de 150 gramas diariamente, um adulto com peso de aproximadamente $70 \mathrm{~kg}$, absorve as proteínas necessárias. Embora a percentagem de proteínas presente em carnes de mamíferos e de aves seja semelhante ao do peixe, este último apresenta proteína de maior valor biológico pelo seu aproveitamento (KURIEN, 2005).

Existe um número considerado de países em que o pescado é uma fonte geradora de emprego e lucro, de forma que, a pesca e o comércio de pescado são atividades que representam, a muitos, sua principal fonte de renda. Um exemplo, na América do Sul de pioneirismo em produção e exportação de pescado é o Chile, segundo maior produtor mundial de salmão, gerando em torno de 25 mil empregos diretos. $\mathrm{O}$ consumo per capita mundial de pescado aumentou, de 11,6 $\mathrm{kg}$ em 1971 para 15,7 $\mathrm{kg}$ em 1997, ambos valores considerados baixos em relação às carnes de ave e bovina (DELGADO et al., 2003).

Alguns estudos têm sido realizados no sentido de verificar qual o perfil dos consumidores de alguns tipos de carnes (CANEVER et al., 1997; SILVA; FABRINI FILHO, 1994). Dentre os objetivos para realizar pesquisas analisando os consumidores de quaisquer produtos, pode-se citar a adoção de estratégias de marketing afim de atender os anseios da população. Segundo Engel et al. (2000), o comportamento do consumidor deve ser estudado para entender as atividades diretamente envolvidas em obter, consumir e dispor de produtos, sendo interessante incluir processos decisórios antes e após as ações.

Esta pesquisa tem como objetivo caracterizar o perfil do consumidor campista de pescado, com base na aplicação de questionários, levando em consideração fatores como: gênero, faixa etária, renda familiar, grau de escolaridade.

\section{METODOLOGIA}

O trabalho consistiu num levantamento, utilizando-se entrevistas, por meio da aplicação de questionários, em moradores do município de Campos dos Goytacazes, durantes os meses de outubro de 2007 a março de 2008.

As questões versaram, inicialmente, a respeito do hábito de consumo de carnes, de forma geral, comparando freqüências de consumo das carnes de frango, de peixe, bovina e suína. A seguir, as indagações concentraram-se na carne de pescado, incluindo, dentre outros, avaliação de preço, preferências da origem (marinha ou dulcícola), espécies preferidas, além de hábitos de pesca. Por fim, os entrevistados foram interrogados quanto a dados pessoais, que permitissem caracterizá-lo de acordo com seu nível de renda, escolaridade e faixa etária.

Foram aplicados, no total, 92 questionários, sendo a amostragem estratificada e proporcional a população do município de Campos de Goytacazes (IBGE, 2001). As freqüências encontradas foram comparadas pelo teste de qui-quadrado para verificação de diferenças entre os gêneros, rendas, escolaridades e faixas etárias nos vários itens da pesquisa.

\section{RESULTADOS E DISCUSSÃO}

A figura 1 apresenta a preferência de local de compra dos diferentes tipos de carnes, onde as carnes de bovino, aves e suínos são adquiridas preferencialmente em supermercados. A carne de peixes é a mais comprada mais em feiras do que em outros locais. 


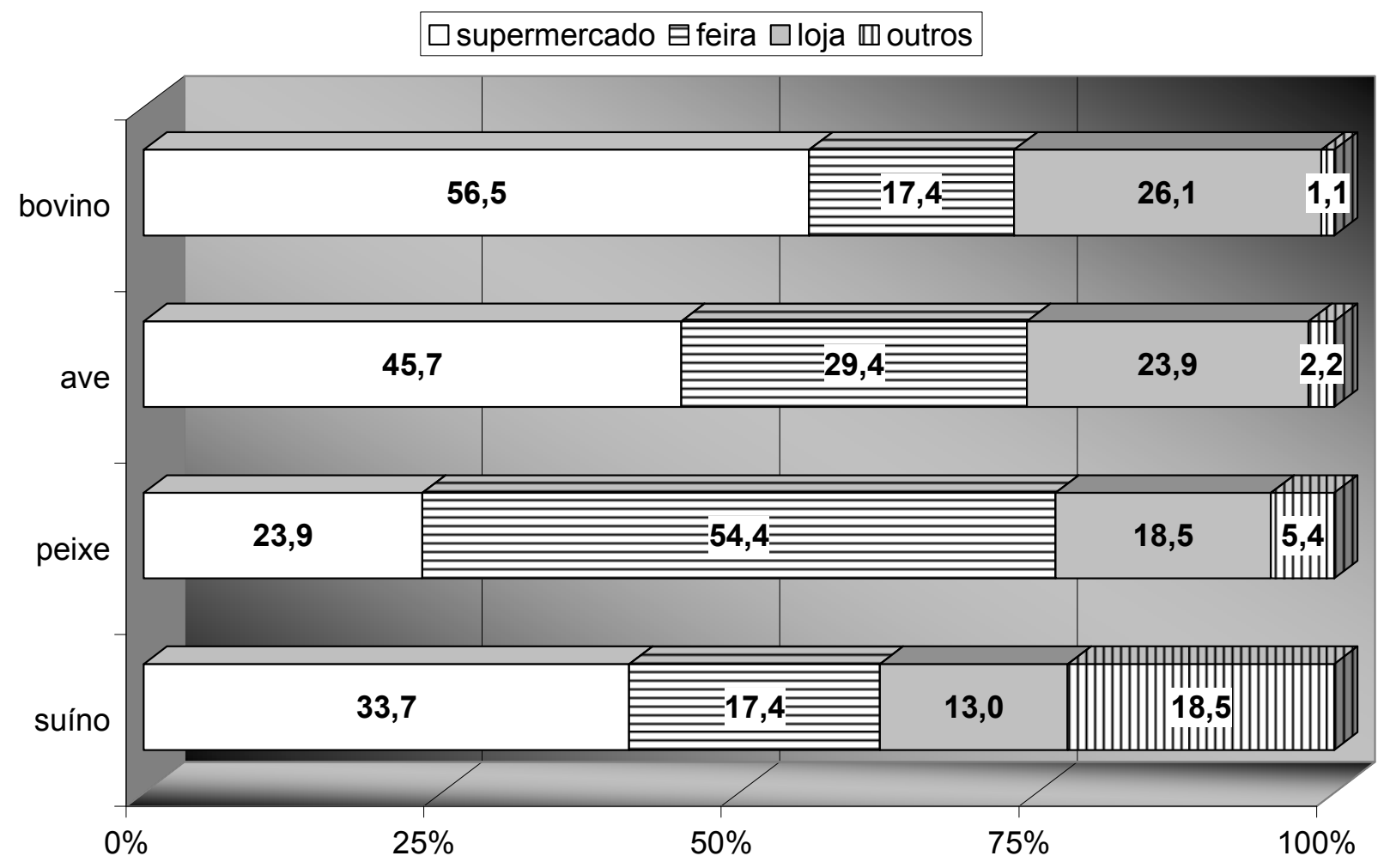

Figura 1: Preferência (\%) de local de compra dos diferentes tipos de carne.

É interessante notar, na figura 2, que a carne bovina é a mais consumida, com freqüência de 3,7 vezes por semana, em média. Em segundo, verifica-se a carne de aves (2,8 vezes por semana), seguida pela de peixe (1,4 vezes por semana). Segundo trabalho de Gonçalves e Machado (2007), a carne de bovino é a mais consumida no país, embora o total de consumo tenha apresentado tendência de redução, diminuindo de 6,3 para 6,0 milhões de toneladas no período e 1997 a 2005. Por outro lado, os mesmo autores descrevem que as demais carnes apresentaram aumento no consumo, incluindo a carne de pescado, que aumentou de 0,9 para 1,1 milhões de toneladas.

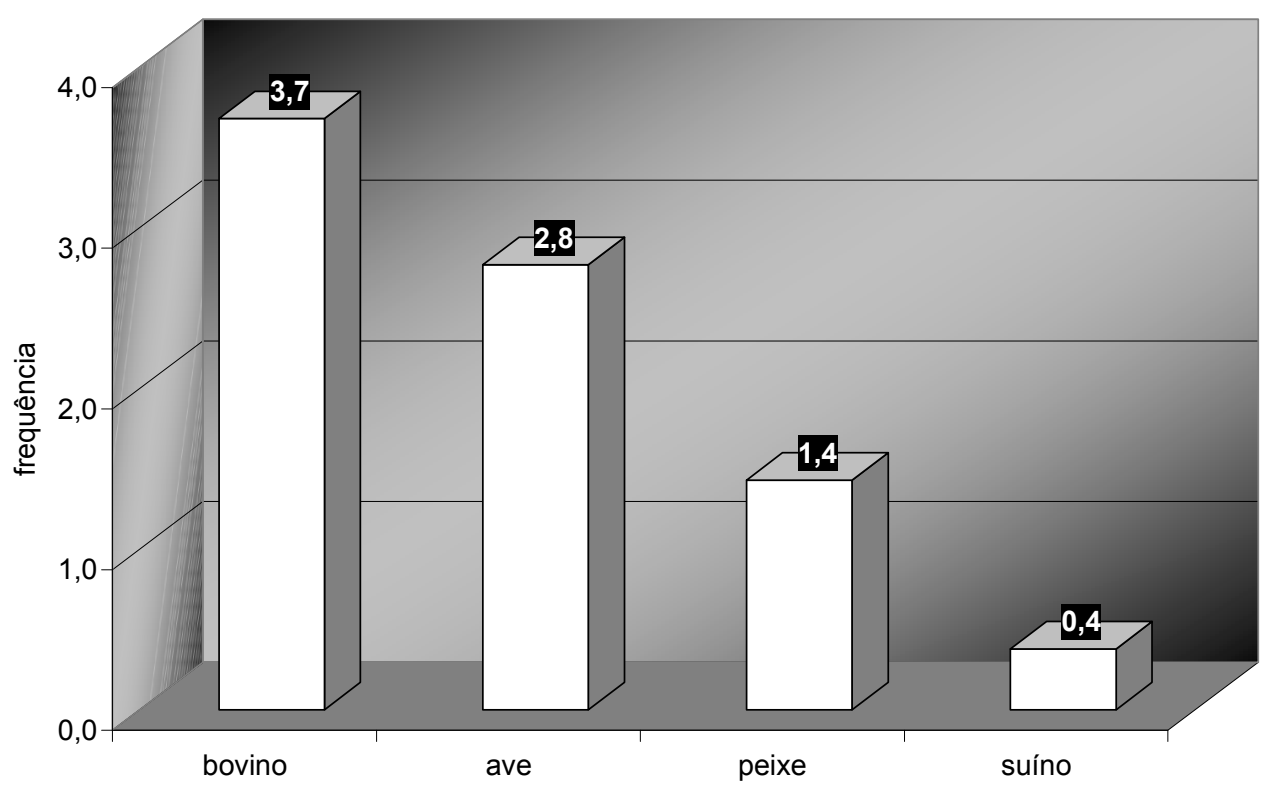

Figura 2: Freqüência semanal de consumo por tipo de carne. 
A figura 3 mostra de que maneira os consumidores classificam cada tipo de carne. Os somatórios são superiores a $100 \%$, pois havia a opção do entrevistado responder a mais do que uma resposta. A carne bovina é caracterizada como saudável e de fácil obtenção. As carnes de aves e peixes, por sua vez, são consideradas pela maioria como saborosas e saudáveis. A de suíno é classificada como saborosa. Ressalta-se que a carne de aves é considerada a mais barata, enquanto que a de peixe é avaliada como a mais saborosa e mais saudável dentre as 4 carnes. Este fato é, em especial interessante considerando-se que os peixes contêm altos níveis de ácidos graxos poliinsaturados, especialmente ômega-3, que diminuem o colesterol do sangue, sendo recomendados para regimes onde esta característica é necessária (KRAUSE; MAHAN, 1991).

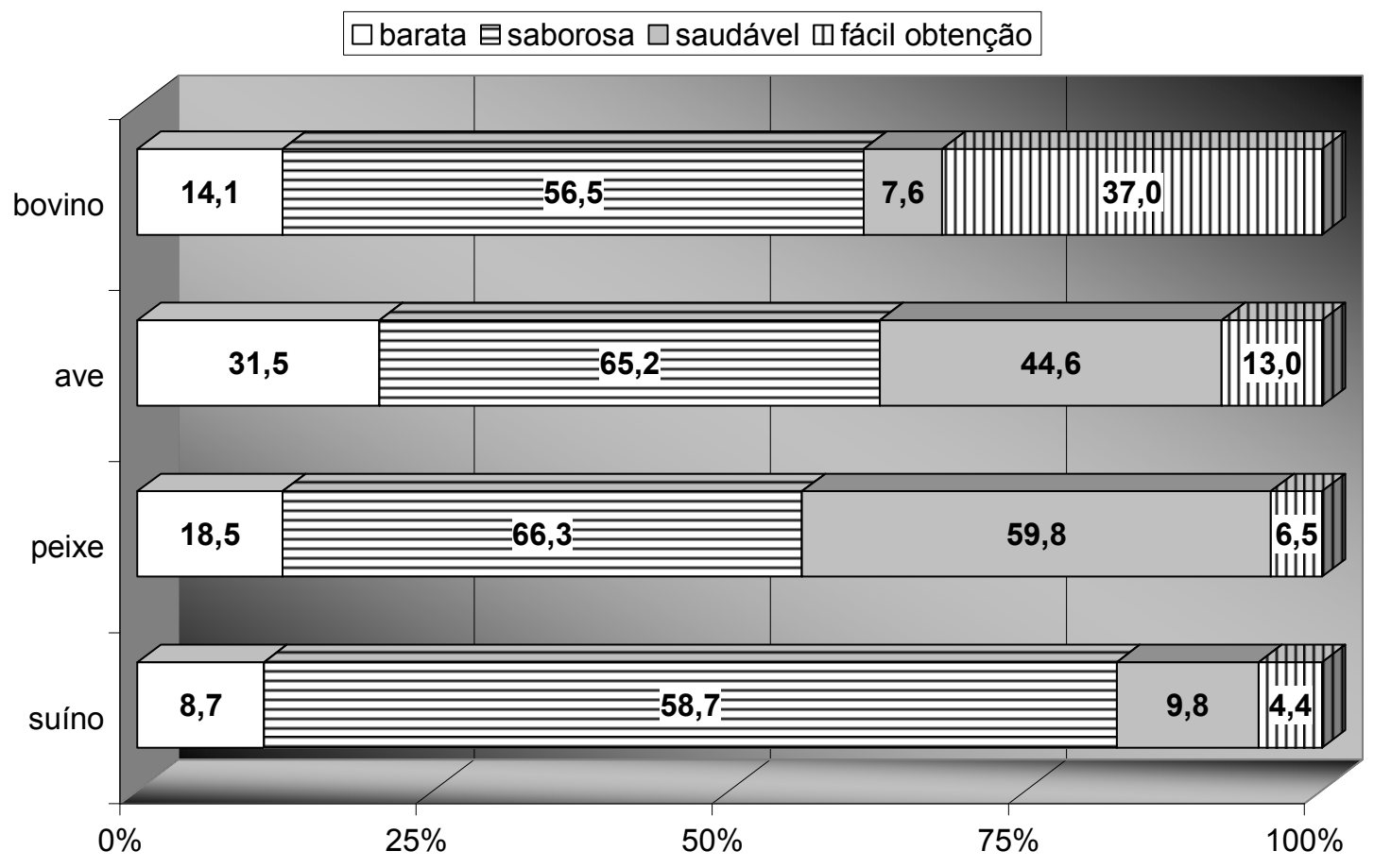

Avaliação das carnes quanto algumas características desejáveis.

Figura 3:

Com relação às questões especificamente relacionadas à carne de peixes, verifica-se na figura 4 que a maioria dos entrevistados prefere apenas consumir carne de pescado (52,2\%). Ainda, 35,9\% gostam de pescar e consumir. A proporção de pessoas que disseram apenas gostar de pescar, e não de consumir, foi de $4,4 \%$.

Quanto ao gênero dos entrevistados, ocorreu diferença significativa $(\mathrm{P}<0,0001)$ entre as proporções que preferem apenas pescar, apenas consumir, consumir e pescar ou que não gostar de fazer nenhum dos dois. Os entrevistados do gênero feminino preferem apenas consumir, enquanto que a maioria dos homens gosta de pescar e consumir peixes.

No que se refere à faixa etária, também verificou-se diferença significativa $(\mathrm{P}=0,0454)$ entre as preferências, sendo que nas faixas até 30 anos predominam aqueles que gostam de pescar e consumir e, em faixas superiores (mais de 30 anos), a maioria prefere apenas consumir. Foi observado que há efeito da faixa de renda sobre o hábito dos entrevistados $(\mathrm{P}=0,0013)$, sendo que em todas as faixas ocorreu maior freqüência daqueles que preferem apenas consumir pescado. Chama a atenção a faixa entre 3,1 e 5 salário mínimos, onde $75 \%$ declaram que preferem apenas consumir.

A pesquisa mostrou ainda que os entrevistados com ensino fundamental ou médio preferem apenas consumir peixes, enquanto os de nível superior optaram mais pela alternativa pescar e consumir, embora estas diferenças não tenham sido significativas $(\mathrm{P}=0,740)$.

Também foi perguntado se os entrevistados achavam a carne de peixe saudável e necessária, tendo a 
maioria respondido afirmativamente, independente do gênero, renda, escolaridade ou idade (Figura 5) . Embora não tenha havido diferenças significativas considerando estes classificações (todos apresentaram $\mathrm{P}>0,05$ ), sobressai o fato de que $100 \%$ dos que recebem mais do que 10 salários mínimos ou com nível superior considerarem a carne de peixe saudável e necessária.

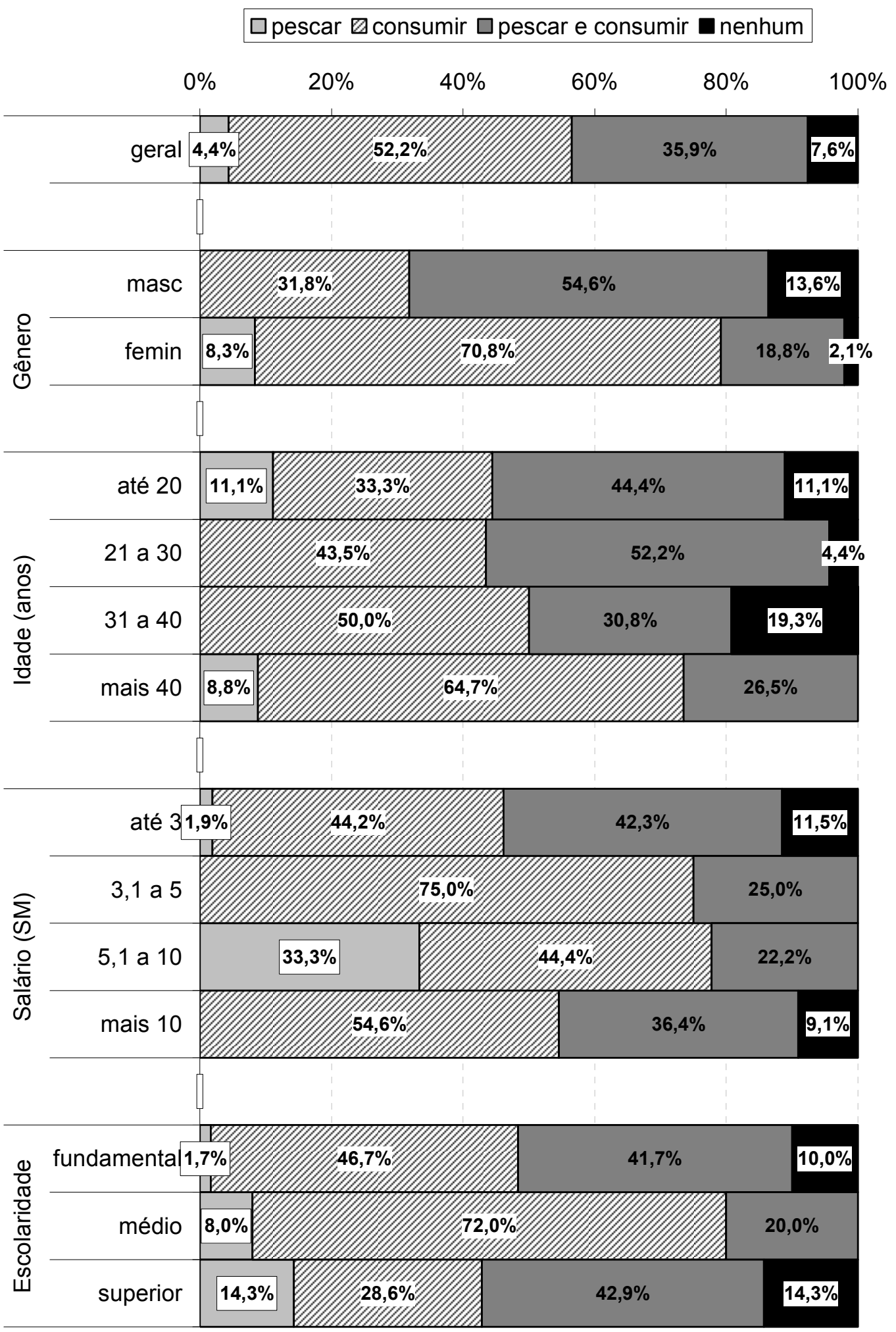

Figura 4: Preferência quanto à pesca e ao consumo, com resultado geral e de acordo com o gênero (masculino ou feminino), faixa etária (em anos), renda (em salários mínimos) e escolaridade. 
O comportamento dos consumidores e os hábitos alimentares estão sofrendo mudanças em conseqüência da intensificação do trabalho feminino, da busca por uma alimentação mais saudável, da globalização, do livre comércio entre as nações, da crescente urbanização, das inovações tecnológicas do setor agrícola. Se estas mudanças forem acompanhadas, ficará claro que a tendência dos consumidores é consumir alimentos mais saudáveis, inclusive aqueles funcionais e livres de colesterol, como também alimentos com maior praticidade na hora de preparar. Segundo a Agência Nacional de Vigilância Sanitária (ANVISA), alimentos funcionais são aqueles que produzem efeitos metabólicos ou fisiológicos através da atuação de um nutriente ou não nutriente no crescimento, desenvolvimento, manutenção e em outras funções normais do organismo humano. O ômega 3 é um exemplo desses alimentos, sendo encontrados em grande proporção nos peixes de águas salgada e fria como atum, arenque, bacalhau, sardinha e salmão. Fica claro que a tendência é aumentar a procura de alimentos, como estes peixes, que comparados a outras carnes, são ricos em alimentos funcionais (BLEIL, 1998; OLIVEIRA; THEBAUD-MONY, 1996; BARCELLOS; CALLEGARO, 2002).

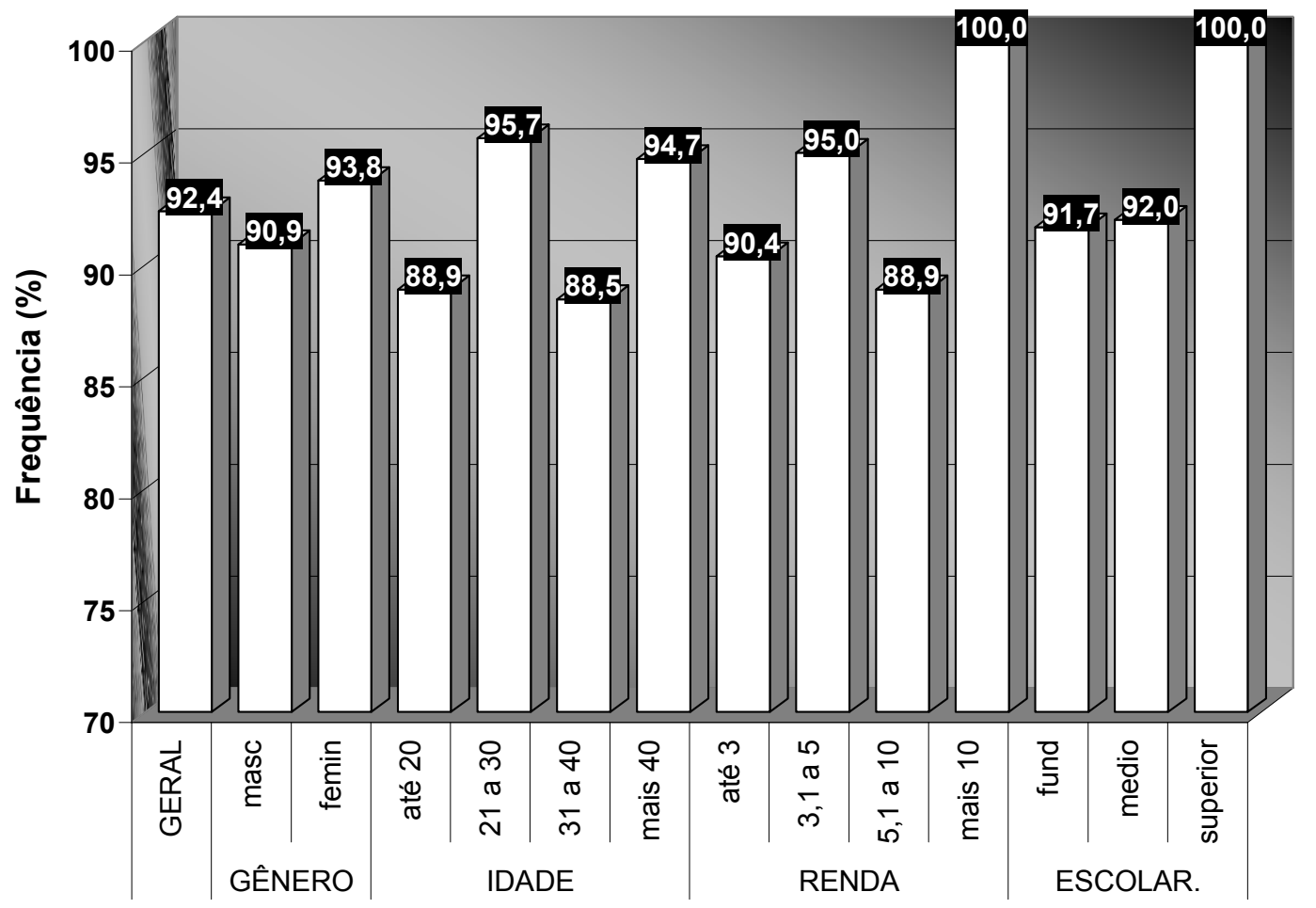

Figura 5: Proporção dos entrevistados que consideram a carne de pescado saudável e necessária.

Interrogados quanto à maneira como classificam o preço do pescado, todos os resultados revelaram a maioria considerando como acessível, com média próxima de 3,0 (Figura 6), tanto no resultado geral como em todas as estratificações realizadas (gênero, renda, escolaridade e idade). Não foi verificada influência destas classes sobre a avaliação do preço $(\mathrm{P}>0,05)$. 


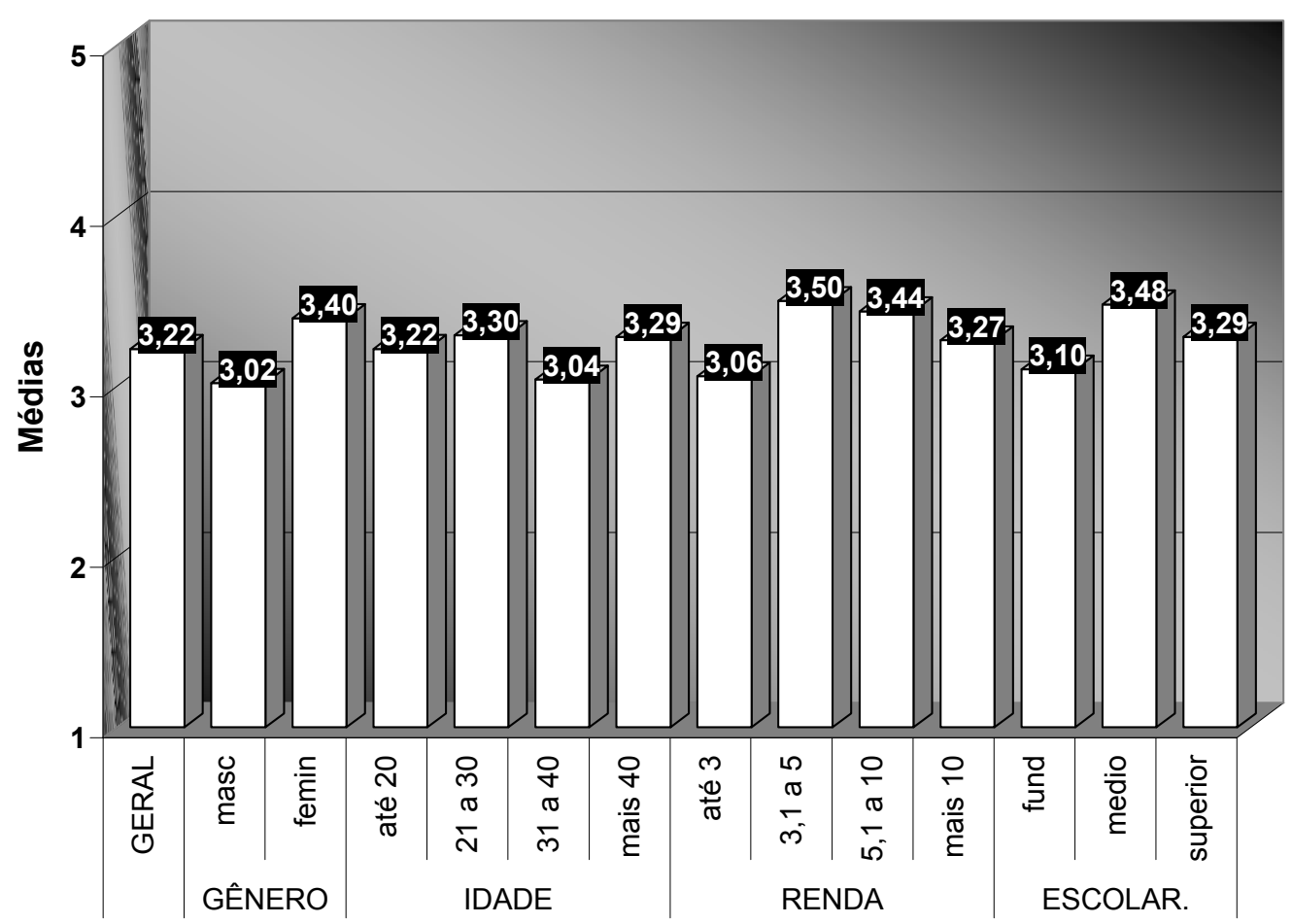

Figura 6: Média da nota atribuída à avaliação do preço da carne de peixe (escala de 1 a 5 , sendo 1 - muito barato até 5 - muito caro). 


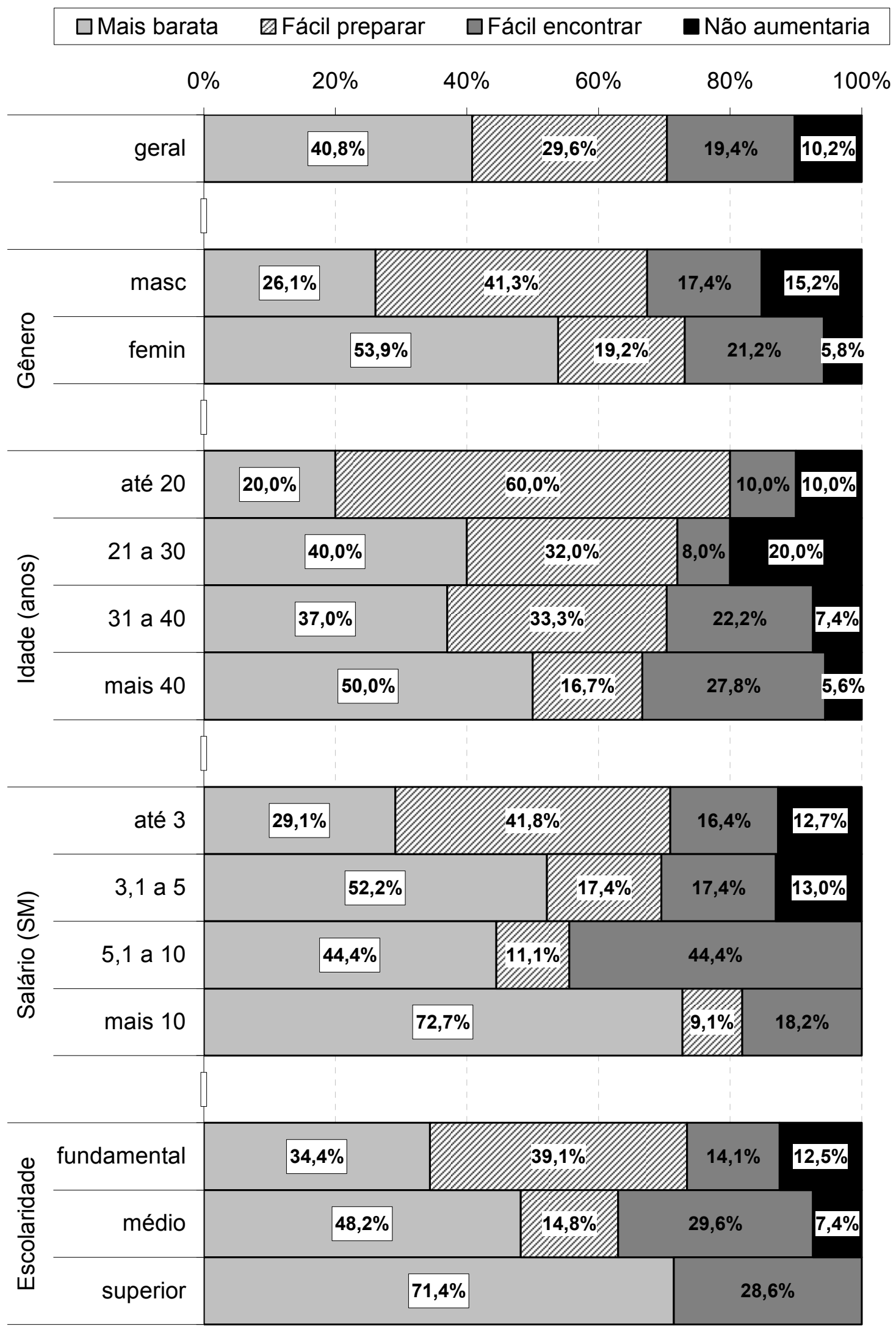

Figura 7: Proporção de respondentes que aumentariam (ou não) o consumo de carne de pescado mediante melhoria no preço, na facilidade de preparação ou de aquisição. 
Quando foi analisado quais características da carne de pescado (preço, preparo, facilidade de encontrar) que causam maior efeito para possível aumento do consumo, obteve-se como resultado que apesar de 40,8\% dos entrevistados admitirem que aumentariam o consumo de pescado caso este fosse mais barato, o efeito não foi significativo, ao nível de $5 \%$ de probabilidade (Figura 7 ).

Quanto aos gêneros (Figura 7), pode-se afirmar que há significância $(\mathrm{P}<0,05)$ e que os homens entrevistados, em sua maioria, aumentariam o consumo se o pescado fosse mais fácil de preparar. Já as mulheres aumentariam o consumo de pescado principalmente se este fosse mais barato.

Ao analisar a renda salarial dos entrevistados, também foram obtidos resultados significativos, tendo em vista que $72,7 \%$ dos que ganham mais de 10 salários mínimos, aumentariam o consumo se o pescado fosse mais barato.

Os que ganham entre 5,1 e 10 salários mínimo ficaram divididos e afirmaram que aumentariam o consumo tanto se fosse mais barato quanto mais fácil de preparar. Observou-se também que os que ganham entre 3,1 e 5 salários mínimo são sensíveis ao preço, pois 52,2\% deles admitiram aumentar o consumo caso o pescado se torne mais barato.

Quanto à faixa etária, não houve diferença significativa. Encontrou-se que dos que tem até 20 anos de idade, $60 \%$ aumentaria o consumo caso fosse mais fácil de preparar, entre 21 e 30 anos são sensíveis ao preço, vendo este como uma condição para o aumento do consumo. O grupo entre 31 e 40 anos, e também os com mais de 40 , aumentariam o consumo caso fosse mais barato, sendo esta a opinião de $37 \%$ e $50 \%$ dos entrevistados, respectivamente.

Quanto ao nível de escolaridade também não foi verificada influência significativa $(\mathrm{P}>0,05)$. Aqueles com até o Ensino Fundamental afirmaram que aumentariam o consumo tanto se o pescado fosse mais barato quanto se fosse mais fácil de preparar. Pessoas com Ensino Médio completo consumiriam mais se a carne de peixe fosse mais barata. À semelhança, 71,4\% dos que possuem Ensino Superior completo também aumentariam o consumo caso fosse mais barato.

Quanto ao gênero, houve diferença significativa no que se está disposto a pagar pelo $\mathrm{kg}$ do pescado (Figura 8), sendo que $54,6 \%$ das pessoas do gênero masculino considera o preço entre $\mathrm{R} \$ 2,01$ e $\mathrm{R} \$ 5,00$ como sendo um preço acessível e $56,3 \%$ do gênero feminino compartilham desta mesma opinião. Na faixa de preço 5,01 à 8,00 , houve uma maior diferença, pois $34,1 \%$ dos homens considerou esta faixa como aceitável, enquanto do gênero feminino foram apenas $12,5 \%$.

Houve uma diferença significativa $(\mathrm{P}=0,0266)$ no que se considera como aceitável pagar pelo $\mathrm{kg}$ do pescado, quando comparadas diferentes faixas etárias, sendo que entrevistados com mais do que 40 anos constituiram o estrato em que se verificou maior parcela $(23,5 \%)$ de pessoas dispostas a pagar mais do que $\mathrm{R} \$ 8,00$. Nas demais faixas de idade, as percentagens que aceitariam pagar mais do que este valor variaram de 0 a $11,1 \%$.

Quanto a faixa de renda dos entrevistados houve diferença estatística $(\mathrm{P}<0,0001)$ quanto ao preço considerado como aceitável para o pescado. Dos que ganham até 3 salários mínimos, apenas 1,9\% consideram pagar mais de 8,00 pelo $\mathrm{kg}$ do pescado como sendo acessível, enquanto $50 \%$ consideram o preço entre $\mathrm{R} \$ 2,01$ e R \$5,00 reais como sendo aceitável. Dos que ganham entre 3,1 e 5 salários, 75\% apresentaram uma maior aceitação na faixa de valor entre $\mathrm{R} \$ 2,01$ à $\mathrm{R} \$ 5,00$. Ainda nesta faixa de renda, nenhum entrevistado aceita adquirir carne de peixe quando o valor é maior que $\mathrm{R} \$ 8,00$, enquanto os que ganham entre 5,1 e 10 salários, 55,6\% considerou este valor como sendo acessível.

Quanto ao nível de escolaridade houve diferença significativa $(\mathrm{P}=0,0013)$ no preço aceitável para a carne de peixe. $\mathrm{O}$ estrato que incluiu pessoas com nível superior foi aquele que apresentou maior 
percentagem $(42,9 \%)$ de entrevistados que aceita pagar mais do que $\mathrm{R} \$ 8,00$ pelo quilograma de peixe.

Quanto aos aspectos mercadológicos, todo o setor de produção, comércio e distribuição devem se preocupar com os preços e o custo de produção, já que esse sistema é que deve se adequar ao mercado e não o contrário. Portanto, se o preço é tão importante para os consumidores, devem-se adotar práticas que possibilitem a redução dos custos de produção para fornecer um produto com menor preço e mais estável, tendo em vista que a oferta não é regular e o preço oscila com freqüência durante o ano. Dessa forma se torna crucial avaliar toda a cadeia de comercialização, e não apenas os pontos de vendas. Isso possibilitará o desenvolvimento da atividade com a técnica adequada, responsabilidade e o mais importante: sustentabilidade (ARAUJO, 2006). 


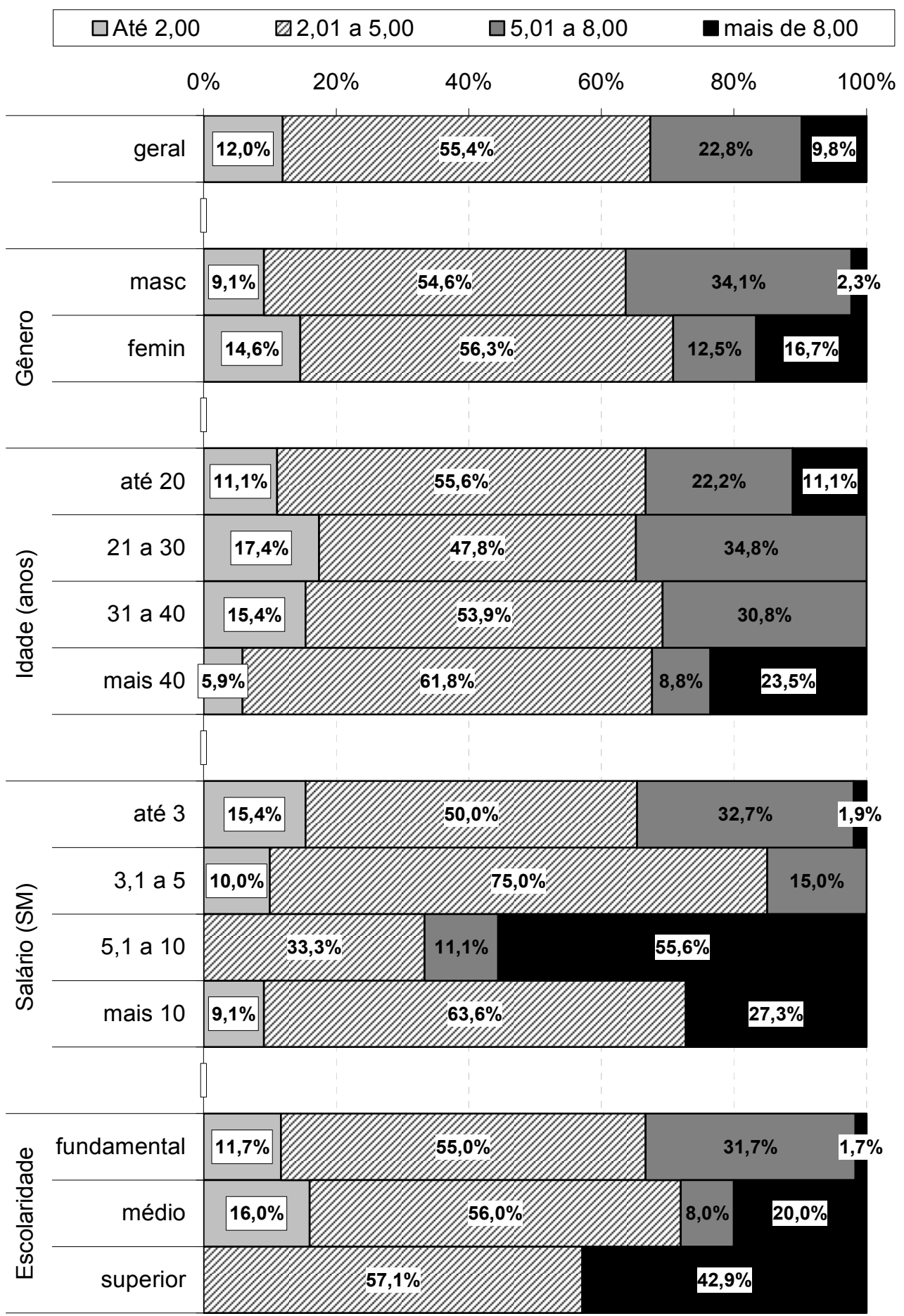

Figura 8: Preço do pescado considerado aceitável pelos entrevistados: resultado geral e de acordo com o gênero, idade (anos), renda (salários mínimos) e escolaridade. 


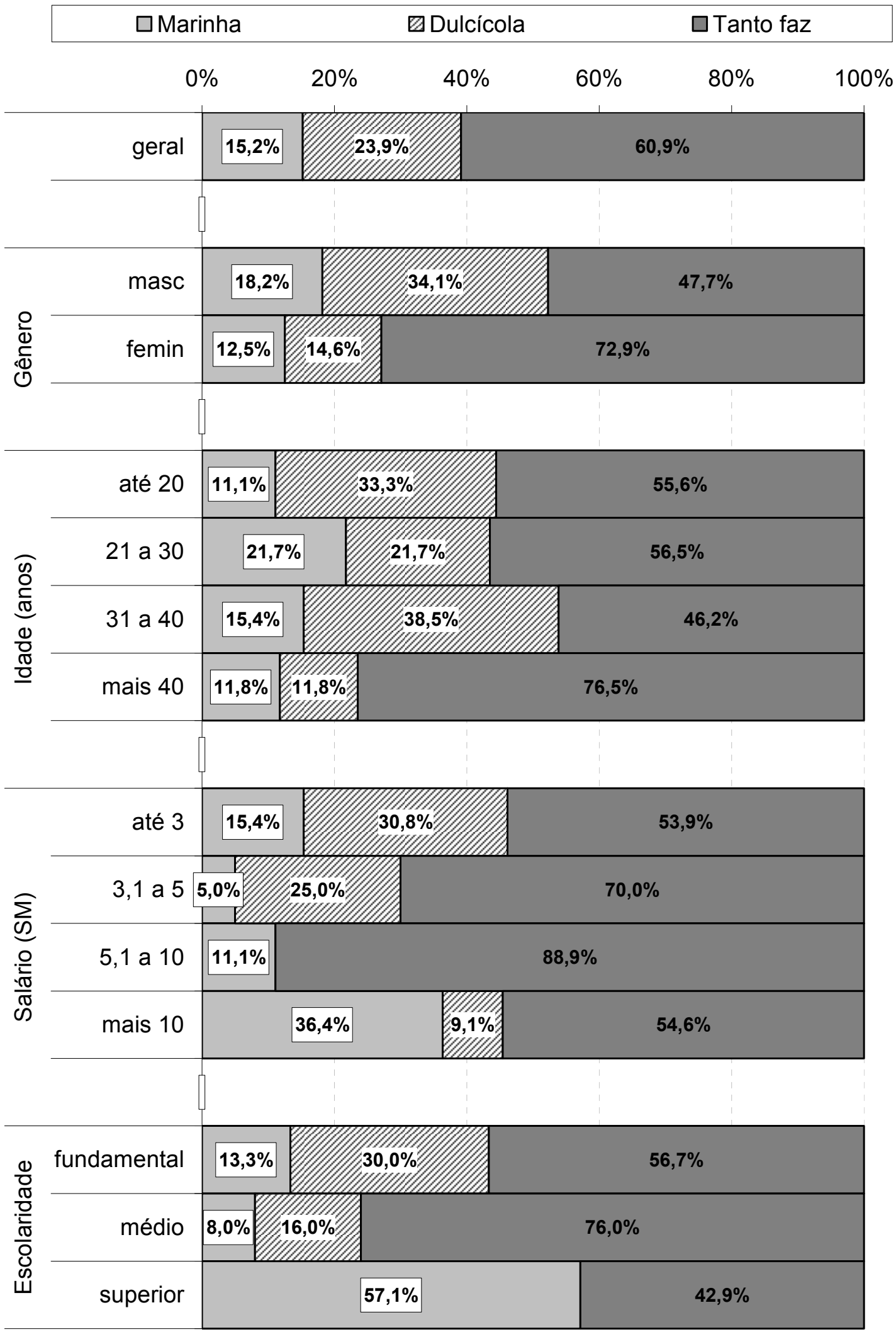

Figura 9: Preferência dos entrevistados de acordo com a origem do pescado (marinho ou dulcícola), com estratificações pelo gênero, idade (anos), renda (salários mínimos) e escolaridade. 
Quanto a origem do pescado (Figura 9), dos entrevistados do gênero masculino, 47,7\% não reveleram preferência entre o pescado de origem marinha ou de água doce e, do gênero feminino, $72,9 \%$ compartilham da mesma opinião. Houve uma maior diferença quando a preferência é por pescado de água doce, em que $34,1 \%$ dos homens e $14,6 \%$ das mulheres fizeram esta escolha.

No que diz respeito a faixa etária (Figura 9), não houve diferença significativa $(\mathrm{P}=0,2248)$ quanto à preferência de acordo com a origem do pescado.

Em todas as faixas de renda, foi verificado que a maioria das pessoas não tem preferência entre pescado do mar e água doce, não havendo efeito significativo da faixa de renda sobre a preferência. Por outro lado, a escolaridade influenciou significativamente $(\mathrm{P}<0,05)$ a preferência. Entrevistados com ensino fundamental ou médio não aprestaram predileção quanto a origem, enquanto que pessoas com nível superior mostraram preferência por peixes oriundos de água marinha.

Ao analisar o porquê da preferência dos entrevistados pelo pescado notou-se que $51,4 \%$ dos entrevistados gostam de consumi-lo por causa do gosto. Já com relação as espécies marinhas ou de água doce, pôde-se perceber que, em ambos os casos, o fator que mais tem efeito na escolha da fonte é o sabor: $61,5 \%$ dos que preferem pescado do mar citam o gosto como motivo da escolha, enquanto que $45,5 \%$ dos que preferem pescado da água doce tem como motivo da escolha também o sabor.

O consumidor tem demonstrado uma notável preferência por produtos frescos, partes congeladas e alimentos industrializados de conveniência, com o crescimento desde segmento, a indústria alimentícia tem se sentido atraída a investir no desenvolvimento de produtos semi-preparados, que reduzem o tempo de dedicação caseira no preparo dos alimentos, produtos prontos para consumo, prontos ou assados, que tem apresentado um crescimento considerável apesar da também crescente oferta de produtos em redes de comida rápida (LIMA et al. 1995).

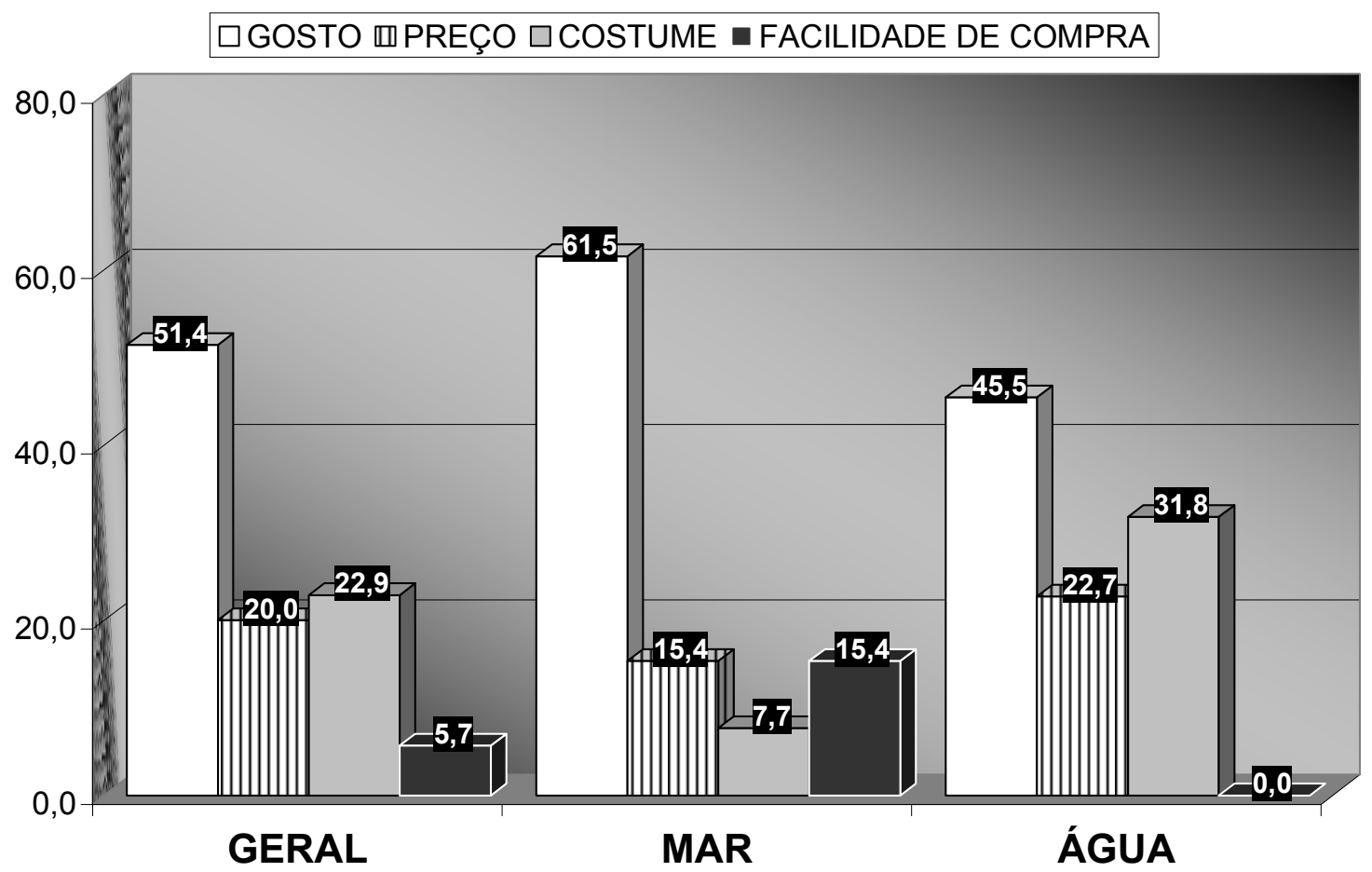

Figura 10: Critério adotado pelos entrevistados para escolha por pescado de origem marinha ou dulceaqüícola: resultados geral e estratificados de acordo com a origem escolhida. 


\section{CONCLUSÕES}

Com base nos resultados das análises realizadas a partir dos dados coletados na pesquisa de campo no âmbito do município de Campos dos Goytacazes, conclui-se que:

1) O consumidor de carne de pescado do município de Campos dos Goytacazes tem o peixe com opção de carne mais saborosa e saudável, demonstrando preferência por mais $90 \%$ dos entrevistados como carne saudável e necessária ao consumo;

2) As mulheres preferem apenas consumir pescado, enquanto os homens gostam tanto de pescar quanto consumir peixes. Quanto maior a faixa etária, maior a preferência apenas pelo consumo de pescado, sem predileção pela pesca;

3) O consumo de carne de peixes aumentaria para mulheres se apresentasse menor preço, enquanto os homens se fosse mais fácil de preparar;

4) A melhor faixa de preço do Kg do pescado aceita pelos entrevistados foi de $\mathrm{R} \$ 2,01$ e $\mathrm{R} \$ 5,00$.

5) Para a maioria dos moradores de Campos dos Goytacazes, não faz diferença a origem do pescado (água doce ou salgada).

\section{REFERÊNCIAS}

ARAUJO, Marcelo Gomes de. Caracterização Sócio - econômica e tecnológica dos piscicultores da região Central do Estado de Tocantins, utilizando técnicas de análise multivariadas. 2006. $100 \mathrm{f}$. Tese (Doutorado) - Curso de Zootecnia, Universidade Federal de Lavras, Minas Gerais, 2006.

BARCEllos, M. D. de; CALlEGARO, C. A. M. A importância da informação como indicadores de qualidade: o caso da compra de carne bovina em Porto Alegre. In: XXVII Congresso da Associação Nacional dos Programas de Pós-Graduação em Administração, Anais... 2002, Salvador/BA.

BLEIL, S. I. O padrão alimentar ocidental: considerações sobre a mudança de hábito no Brasil. Caderno de Debates UNICAMP, Campinas, v. 6, p. 1-25, 1998.

CANEVER, M. D. et al. Competitividade entre as cadeias de carne de frango brasileira e argentina. Congresso Brasileiro de Economia e Sociologia Rural, 35. Natal, 1997. Anais... Natal, 1997.

DELGADO, C L ; WADA, N ; ROSENGRANT, M W ; MEIJER, S ; AHMED, M (2003). Outlook for fish to 2020: Meeting global demand. International Food policy Research Institute, WorldFish Center, Penang, Malaysia: 28p.

ENGEL, J. et al. Comportamento do consumidor. 8.ed. Rio de Janeiro: LTC, 2000.

GONÇALVES, J. S.; MACHADO, R. S. Consumo e hierarquia dos relativos de preços de proteína animal no Brasil, 1997-2006, Informações Econômicas, SP, v.37, n.9, set. 2207

IBGE. Censo demográfico 2000: características da população e domicílios. IBGE. 2001.

KURIEN, J. Responsible fish trade and food security. FAO Fisheries Technical Paper, №. 456: 102p, 2005.

LANKE, N.G et al. Determinação de vitamina A em pescado: adaptação de metodologia. Rev. Inst. Adolfo Lutz, 62(3):151-158, 2003.

LIMA, J. et al. Avicultura - Relato setorial. 1995.

OLIVEIRA, S. P.; THÉBAUD-MONY, A. Modelo de consumo agroindustrial: homogeneização ou diversificação dos hábitos alimentares? Caderno de Debates, Campinas/SP, v. 4, p. 1-13, 1996.

SANTOS, E. Pesca e piscicultura. Belo Horizonte, Itatiaia Ltda, 1977.

SILVA, L. F.; FABRINI FILHO, L. C. Complexo avícola e questões sobre hábito alimentar. Caderno de Debate UNICAMP, Campinas, v. 2, p. 41-61, 1994. 